\title{
Lymphocyte transformation responses to phytohaemagglutinin and Pokeweed mitogen in patients at differing stages of HIV infection: Are they worth measuring?
}

\author{
A S Bansal, A Moran, M Potter, R Taylor, M R Haeney, B K Mandal
}

\begin{abstract}
Aims-To determine whether the routine measurement of lymphocyte transformation responses to mitogenic stimuli provide any information additional to that available from routine $T$ cell CD4 and CD8 analysis in patients with HIV infection.

Methods-The case records of 197 immunologically investigated HIV seropositive patients were reviewed. The influence of disease stage on $T$ lymphocyte subsets and lymphocyte transformation responses (LyTR) to phytohaemagglutinin (PHA) and Pokeweed mitogen was assessed.

Results-The median CD3 and CD4 counts and LyTR to PHA and Pokeweed mitogen were highest in patients with persistent generalised lymphadenopathy (PGL) and decreased progressively in the order: asymptomatic patients, those with ARC, those with AIDS. LyTR to PHA was preserved in over $70 \%$ of all patients, but the response to Pokeweed mitogen was depressed in $8 \%$ of patients with PGL, $34 \%$ of asymptomatic patients, $68 \%$ of those with ARC and $78 \%$ of those with AIDS. Subnormal values of both CD4 + T cells and LyTR to Pokeweed mitogen were more common in patients with ARC and AIDS (68\%) than in those who were asymptomatic or had PGL $(20 \%)$.

Conclusions-CD4 $T$ cell analysis and LyTR to Pokeweed mitogen, but not to PHA, both correlate with disease states in patients with HIV infection.
\end{abstract}

(F Clin Pathol 1993;46:846-848)

Department of

Immunology, Hope

Hospital, Eccles Old

Road, Salford

A Moran

M Potter

M R Haeney

Department of

Medical Physics,

Hope Hospital,

Salford

R Taylor

Regional Department of Infectious Disease and Tropical

Medicine, Monsal

Hospital, Manchester

B K Mandal

Correspondence to:

Dr A S Bansal, Departmen of Immunology, Hope Hospital, Salford M6 8HD.

Accepted for publication 22 April 1993 in the disease. ${ }^{1}$ Asymptomatic patients also manifest an impaired response to Pokeweed mitogen several months before disease progression to AIDS. ${ }^{1}$ As with the CD4 and total $T$ cell counts substantial variability in LyTR is evident in individuals with equivalent stages of HIV disease. ${ }^{1-3}$

The routine measurement of LyTR in patients with HIV infection had been performed in this laboratory since 1983. We undertook this study to assess the value of this investigation relative to $T$ cell subset analysis in the clinical management of patients with HIV infection.

\section{Methods}

The case records were reviewed of $197 \mathrm{HIV}$ seropositive subjects attending the Regional Department of Infectious Diseases at Monsall Hospital between 1983 and 1991 and on whom LyTR had been determined. HIV disease was staged according to Centers for Disease Control (CDC) classification ${ }^{4}$ at the time points of immunological investigation. Staging was undertaken without knowledge of these latter results.

Indirect immunofluorescence and ultraviolet microscopy of lymphocytes separated by density gradient had been used for total $T$ cell and CD4/CD8 subset analysis until mid1989. Flow cytometry on lysed whole blood using direct immunofluorescence was used subsequently. Monoclonal antibodies OKT3, 4 , and 8 (Ortho Diagnostics Ltd) were used for indirect immunofluorescence and Dako CD3, 4, and 8 used for direct immunofluorescence. Absolute CD3, CD4, and CD8 counts were calculated from simultaneously determined total lymphocyte counts.

Lymphocyte transformation responses were measured according to standard methods. PHA and Pokeweed mitogen were used at six different concentrations and results were reported as the maximum response expressed in counts per minute (cpm), minus the unstimulated response in $\mathrm{cpm}$.

During the course of their routine care, many patients had LyTR and subset analysis performed on several occasions. Where the CDC classification of the patient did not change, the means of the LyTR and subset analyses were used for statistical analysis. For those patients in whom a change in the CDC classification was detected, the data were analysed separately according to their new CDC classification.

Statistical analysis was performed using the Mann Whitney-U test.

\section{Results}

Over $88 \%$ of the patients were homosexual or bisexual males. Of 12 intravenous drug misusers, four were female and eight male. Nine cases of heterosexually acquired HIV infection were noted (three Caucasian and one African female, and one Caucasian and four African males). Vertical transmission was recorded in one case and no predisposing 
Table 1 Comparison of total CD3, CD4, and CD8 between patients in each CDC stage (data shown as median (range))

\begin{tabular}{|c|c|c|c|}
\hline$C D C$ stage & $\begin{array}{l}\text { CD3 count } \\
\left(\times 10^{\circ} / I\right)\end{array}$ & $\begin{array}{l}\text { CD4 count } \\
\left(\times 10^{\circ} / I\right)\end{array}$ & $\begin{array}{l}\text { CD8 count } \\
\left(\times 10^{\circ} / I\right)\end{array}$ \\
\hline \multirow[t]{2}{*}{$\begin{array}{l}2(n=70) \\
\text { (Asymptomatic) } \\
3(n=22) \\
(\text { PGL) } \\
4(n=41) \\
(\text { ARC) } \\
4^{\star}(n=64) \\
\text { (AIDS) }\end{array}$} & $\begin{array}{l}1.46 \\
(0 \cdot 66-3.91) \\
1 \cdot 77 \\
(0 \cdot 77-3 \cdot 68) \\
1 \cdot 33 \\
(0 \cdot 15-3 \cdot 76) \\
0 \cdot 89 \\
(0 \cdot 15-4 \cdot 27)\end{array}$ & $\begin{array}{l}0.49 \\
(0.04-2 \cdot 30) \\
0.74 \\
(0.15-2 \cdot 34) \\
0 \cdot 27 \\
(0.04-1 \cdot 70) \\
0 \cdot 10 \\
(0.01-1.57)\end{array}$ & $\begin{array}{l}0.90 \\
(0.34-3.01) \\
0 \cdot 84 \\
(0 \cdot 10-2 \cdot 16) \\
0 \cdot 80 \\
(0.07-2 \cdot 14) \\
0 \cdot 64 \\
(0 \cdot 13-2 \cdot 92)\end{array}$ \\
\hline & $\begin{array}{l}2 v 4^{\star} p<0.0001 \\
3 v 4^{\star} p<0.03 \\
3 v 4^{\star} p<0.0001 \\
4 v 4^{\star} p<0.04 \\
3 v 4^{\star} p<0.0001 \\
4 v 4^{\star} p<0.02\end{array}$ & $\begin{array}{ll}2 v 3 & \mathrm{p}<0.05 \\
2 v 4 & \mathrm{p}<0.0001 \\
2 v 4^{\star} \mathrm{p}<0.0001 \\
3 v 4 \mathrm{p}<0.0001\end{array}$ & $\begin{array}{l}2 v 4^{\star} \mathrm{p}<0.0003 \\
3 v 4^{\star} \mathrm{p}<0.04\end{array}$ \\
\hline
\end{tabular}

Table 2 Comparison of lymphocyte transformation response (LyTR) to PHA and Pokeweed mitogen between patients in each CDC stage (data shown as median (range))

\begin{tabular}{lll}
\hline CDC stage & LyTR to PHA (cpm) & LyTR to PWM (cpm) \\
\hline 2 (asymptomatic, $\mathrm{n}=70)$ & $24970(2383-70850)$ & $5430(178-51270)$ \\
3 (PGL, $\mathrm{n}=22)$ & $29410(9240-58760)$ & $5880(1113-23610)$ \\
4 (ARC, $\mathrm{n}=41)$ & $23490(1812-66680)$ & $2540(0-18060)$ \\
$4^{\star}(\mathrm{AIDS}, \mathrm{n}=64)$ & $19170(1389-94650)$ & $1503(73-14012)$ \\
\hline & $2 v 4^{\star} \mathrm{p}<0.001$ & $2 v 4 \mathrm{p}<0.002$ \\
& $3 v 4^{\star} \mathrm{p}<0.002$ & $2 v 4^{\star} \mathrm{p}<0.0001$ \\
& $3 v 4 \mathrm{p}<0.007$ \\
& $3 v 4^{\star} \mathrm{p}<0.0001$ \\
& & $4 v 4^{\star} \mathrm{p}<0.03$
\end{tabular}

factor could be determined in another.

Of the 197 patients, 70 were asymptomatic, 22 had PGL, 41 had AIDS related complex (ARC) and 64 were diagnosed as having AIDS. Table 1 summarises the data comparing stage of disease and the variables of total CD3, CD4, and CD8 counts. Table 2 summarises the results of LyTR to PHA and Pokeweed mitogen for these same groups. The median CD8 T lymphocyte count showed a gradual decline with advancing stages of HIV infection. A significant difference was, however, only evident between the asymptomatic patients and those with AIDS. The median CD3, CD4, PHA and Pokeweed mitogen counts were highest in patients with PGL and decreased progres- sively in the order: asymptomatic patients, those with ARC, those with AIDS. Apart from the median $\mathrm{CD} 4$ count, there was no significant difference in each of these variables between the asymptomatic patients and those with PGL. HIV progression from PGL to ARC produced a significant decline in the median CD3 and CD4 counts and the LyTR to Pokeweed mitogen but not to PHA (tables 1 and 2). Significant differences were again noted in these variables, but not to PHA, with further disease progression from ARC to AIDS.

The lower limit of normal (95\% confidence limit) for the CD4, Pokeweed mitogen, and PHA counts recognised in this laboratory are $0.5 \times 10^{9} / 1,4000 \mathrm{cpm}$, and $12000 \mathrm{cpm}$, respectively. Table 3 shows the number of patients from each disease stage with CD4 counts and LyTR above and below the accepted lower limits. Nearly two thirds (130) of the 197 patients had a subnormal CD4 count. A subnormal LyTR to Pokeweed mitogen was noted in 56\% (110 patients) and a subnormal LyTR to PHA in $16 \%$ (32 patients). Among patients with a subnormal CD4 count, 32\% (42 from 130 patients) were either asymptomatic or had PGL while $68 \%$ (88 patients) had either ARC or AIDS. Over $70 \%$ of the patients with a subnormal LyTR to Pokeweed mitogen had ARC or AIDS (78 from 110 patients) while $30 \%$ were either asymptomatic or had PGL (32 from 110 patients). Eight out of 92 patients (9\%) who were either asymptomatic or had PGL had a subnormal LyTR to PHA while 24 from the 105 patients (23\%) with ARC or AIDS had a subnormal LyTR to PHA.

A subnormal CD4 count and LyTR to Pokeweed mitogen was noted in $20 \%$ of asymptomatic patients and those with PGL. This was increased to $68 \%$ in patients with ARC and AIDS (table 4). In contrast, a normal CD4 count or LyTR to Pokeweed mitogen, or both, was evident in only $32 \%$ of patients with ARC and AIDS, but in $80 \%$ of asymptomatic patients and those with PGL.

Table 3 Numbers of patients with normal and subnormal CD4 counts and lymphocyte transformation responses to Pokeweed mitogen and PHA in each stage of HIV infection

\begin{tabular}{|c|c|c|c|c|c|c|}
\hline$C D C$ stage & $\begin{array}{l}C D 4 \\
<0.5 \times 10^{9} / l\end{array}$ & $\begin{array}{l}C D 4 \\
>0.5 \times 10^{9} / l\end{array}$ & $\begin{array}{l}\text { Pokerveed mitogen } \\
<4000 \mathrm{cpm}\end{array}$ & $\begin{array}{l}\text { Pokerveed mitogen } \\
>4000 \mathrm{cpm}\end{array}$ & $\begin{array}{l}\text { PHA } \\
<12000 \mathrm{cpm}\end{array}$ & $\begin{array}{l}\text { PHA } \\
>12000 \mathrm{cpm}\end{array}$ \\
\hline $\begin{array}{l}\text { Asymptomatic } \\
\text { PGL } \\
\text { ARC } \\
\text { AIDS }\end{array}$ & $\begin{array}{r}37(53) \\
5(23) \\
31(76) \\
57(89)\end{array}$ & $\begin{array}{r}33(47) \\
17(77) \\
10(24) \\
7(11)\end{array}$ & $\begin{array}{r}24(34) \\
8(36) \\
28(68) \\
50(78)\end{array}$ & $\begin{array}{l}46(66) \\
14(64) \\
13(32) \\
14(22)\end{array}$ & $\begin{array}{c}6(9) \\
2(9) \\
7(32) \\
17(27)\end{array}$ & $\begin{array}{l}64(91) \\
20(91) \\
34(68) \\
47(63)\end{array}$ \\
\hline
\end{tabular}

Figures in parentheses indicate percentages of patients relative to the total number of patients with that stage of infection.

Table 4 Numbers of patients with normal and subnormal CD4 counts and LyTR to Pokeweed mitogen in each stage of HIV infection

\begin{tabular}{|c|c|c|c|c|}
\hline$C D C$ stage & $\begin{array}{l}\text { CD4 < } 0.5 \times 10^{9} / l \\
+ \text { Pokeweed mitogen } \\
<4000 \text { cpm }\end{array}$ & $\begin{array}{l}\text { CD4 >0.5 } \times 10^{\circ} / l \\
+ \text { Pokeweed mitogen } \\
>4000 \text { cpm }\end{array}$ & $\begin{array}{l}\text { CD4 <0.5 } \times 10^{\circ} / 1 \\
+ \text { Pokeweed mitogen } \\
\geq 4000 \mathrm{cpm}\end{array}$ & $\begin{array}{l}\text { CD4 >0.5 } \times 10^{\circ} / l \\
+ \text { Pokeweed mitogen } \\
\leq 4000 \mathrm{cpm}\end{array}$ \\
\hline $\begin{array}{l}\text { Asymptomatic } \\
\text { PGL } \\
\text { ARC } \\
\text { AIDS }\end{array}$ & $\begin{array}{c}16(23) \\
2(9) \\
25(61) \\
47(73)\end{array}$ & $\begin{array}{c}27(39) \\
11(50) \\
6(15) \\
3(5)\end{array}$ & $\begin{array}{r}21(30) \\
3(14) \\
6(15) \\
10(16)\end{array}$ & $\begin{array}{l}6(8) \\
6(27) \\
4(9) \\
4(6)\end{array}$ \\
\hline
\end{tabular}

Figures in parentheses indicate percentage of patients relative to the total number of patients with that stage of infection. 
As the LyTR to PHA tended to be subnormal only when the LyTR to Pokeweed mitogen was subnormal the proportion of patients with subnormal CD4 count and LyTR to both Pokeweed mitogen and PHA was almost identical with the proportion with subnormal CD4 count and LyTR to Pokeweed mitogen alone.

\section{Discussion}

The demographic characteristics and factors predisposing to HIV infection noted in this study were similar to those recorded before. ${ }^{56}$

Our finding of a progressive decline in the CD8 count with more advanced stages of HIV infection confirms that the immune damage caused by HIV is not restricted to CD4 T cells. ${ }^{7-9}$ We did, however, observe the median CD3, CD4, Pokeweed mitogen and PHA counts to be highest and the proportions of patients with subnormal values for these variables to be lowest in patients with PGL. This suggests that immune function is best preserved in patients with PGL. Persistent and generalised lymph node enlargement may therefore reflect successful temporary containment of HIV infection.

A decreased proliferative response to Pokeweed mitogen has been shown to be an early predictor for the development of AIDS in asymptomatic HIV seropositive subjects. ${ }^{1}$ Similar predictive information has been claimed for both the absolute CD4 lymphocyte count and the CD4:CD8 ratio. ${ }^{1011}$ Substantial depression of lymphocyte transformation to Pokeweed mitogen and a lesser depression to phytohaemagglutinin has been noted as an early feature in subjects with a severe initial seroconverting illness. ${ }^{12}$ Early progression to AIDS or ARC occurred in two of the seven patients reported by this group. ${ }^{12}$ Lymphocyte hyporesponsiveness to Pokeweed mitogen also appears to correlate with an impaired in vitro proliferative response to cytomegalovirus (CMV), Candida, and tetanus toxoid. ${ }^{1313}$

In agreement with Hofmann et $a l,^{3}$ we too found that LyTR to Pokeweed mitogen was significantly lower in the patients with AIDS and ARC compared with asymptomatic patients and those with PGL (table 2). Furthermore, a subnormal response to Pokeweed mitogen was more common in patients with asymptomatic disease or PGL compared with patients with AIDS or ARC. For an individual patient, however, an isolated value for LyTR to Pokeweed mitogen provided only limited discriminatory information on the CDC classification. This was certainly true of LyTR to PHA which was within normal limits in over $70 \%$ of all patients, and partially true for the CD4 count which showed subnormal values in over half of the patients with asymptomatic disease and in over three quarters of the patients with ARC or AIDS. A combination of the CD4 count and LyTR to Pokeweed mitogen was, however, more helpful in CDC classification in that subnormal values for both variables were found in only $20 \%$ of asymptomatic patients or those with PGL but in over $70 \%$ of patients with ARC or AIDS. Moreover, a subnormal CD4 count and LyTR to Pokeweed mitogen, or both, were evident in $95 \%$ of patients with AIDS.

We conclude that in HIV seropositive subjects in whom the clinical history is insufficiently clear to allow precise CDC classification to be made a combination of CD4 analysis and assessment of LyTR to Pokeweed mitogen may be helpful. Analysis of LyTR to PHA provides little additional information to that already provided by the two previous investigations.

1 Hofmann B, Lindhardt BO, Gerstoft J, et al. Lymphocyte transformation response to pokeweed mitogen as a pre-
dictive marker for development of AIDS and AIDS related symptoms in homosexual men with HIV antirelated symptoms in homosexual
bodies. BrMed $\mathcal{1}$ 1987;295:293-6.

2 Polis MA, Masur H. Predicting the progression to AIDS. Am ₹ Med 1990;89:701-5.

3 Hofmann B, Damgard J, Odum N, et al. Relatively preserved phytohaemagglutinin as opposed to decreased pokeweed mitogen responses may be due to possibly preserved responses via $\mathrm{CD} 2$ /phytohaemagglutinin pathway. I Immunol 1989;142:1874-80.

4 Selick RM, Jaffe HW, Soloman SL, Curran JW. CDC definition of AIDS. N Engl $₹$ Med 1986;315:761.

5 The unlinked anonymous HIV prevalence monitoring programme in England and Wales: Preliminary results. Comm Dis Rep 1991;1:R69-R76.

6 Peters BS, Beck EJ, Coleman DG, et al. Changing disease patterns in patients with AIDS in a referral centre in the United Kingdom: the changing face of AIDS. $B M^{\gamma}$ 1991;302:203-7.

7 Henderson LA, Qureshi NM, Rasheed S, Garry R. Human immunodeficiency virus-induced cytotoxicity for CD8 cells from some normal donors and virus-specific induction of a suppressor factor. Clin Immunol Immunopathol 1988;48:174-86.

8 Morrow WJW, Isenberg DA, Sobol RE, Stricker RB, Kieber-Emmons $T$. AIDS virus infection and autoimmunity: A perspective of the clinical, immunological, and molection associated with HIV disease. Clin Immunol Immunopathol 1991;58:163-80.

9 Meidema F, Chantal Petit AJ, Terpstra FG, et al. Immunological abnormalities in human immunodefiency virus (HIV)-infected asympto

10 Fishbein DB, Jonathan FK, Spira EK, et al. Unexplained lymphadenopathy in homosexual men $\mathcal{F A M A} 1985$; 254:930-5.

11 Schwartz K, Visscher BR, Detels R, Taylor J, Nishanian $P$, Fahey J. Immunologic changes in lymphadenopathy virus positive and negative symptomless male homosexuals: two years of observation. Lancet 1985; i:831-2.

12 Pederson C, Dickmeiss E, Gaub J, Ryder LP, Platz PT. T cell subset alterations and lymphocyte responsiveness to mitogens and antigen during severe primary infection mitogens and antigen during severe primary infection
with HIV: a case series of seven consecutive HIV serwith HIV: a case series of seven

13 Teeuwsen VIP, Logtenberg T, Siebelink KHI, et al. Analysis of the antigen and mitogen induced differentiaAnalysis of the antigen and mitogen induced differentia-
tion of $B$ lynphocytes from asymptomatic human immunodeficiency virus seropositive male homosexuals. immunodeficiency virus sero 